\title{
ON THE ACTION OF CRUSHED QUARTZ UPON NITRATE SOLUTIONS ${ }^{1}$
}

\author{
BY HARRISON E. PATTEN
}

\section{Introduction}

During a study of the absorption of soluble salts from solution it was found that crushed quartz powder apparently abstracted nitrate from a percolating sodium nitrate solution, but when the quartz was removed from its percolation cylinder and tested for nitrate, it was found that neither nitrate nor caustic soda was held by it. This means that the nitrate is decomposed during its passage through the quartz percolation-bed, and that the products of decomposition are not retained in appreciable amount by the quartz. It is to be expected that denitrifying bacteria would thus break down the nitrate in solution. In addition to this, the question naturally arises as to what part, if any, is taken in this nitrate reduction by the vast surface of quartz in contact with the percolating solution. The experiments described below were made to answer this question.

\section{Experimental}

Samples of crushed quartz were treated with C. P. concentrated hydrochloric acid for two days on the steam bath, to remove iron and to kill bacteria; they were then washed by repeated decantation with distilled water fresh from the still, until the washings gave only a faint clouding with silver nitrate, showing removal of practically all chlorine.

Experiment 1.-Twenty grams of coarse quartz powder, having a surface area of some IOo sq. $\mathrm{cm}$ per gram, ${ }^{2}$ thus treated was shaken with $60 \mathrm{cc}$ of $0.01 \mathrm{~N}$ aqueous $\mathrm{AgNO}_{3}$ in a

${ }^{1}$ Published by permission of the Secretary of Agriculture.

2 This area is given as $97 \mathrm{sq} . \mathrm{cm}$ per gram in Bulletin 59 , page 50 , Bureau of Soils, U. S. Dept. of Agriculture (I909); this value is calculated from the mecharical analysis on page 20 of the same bulletin. The number Ioo is taken here to avoid a refinement of digits unwarranted by the accuracy of both experiment and calculation by which it is derived. 
flask blackened to exclude light, allowed to settle, and portions of solution drawn off and analyzed for content of silver and for traces of reduction of nitrate. The $60 \mathrm{cc}$ of silver nitrate used contained 0.0647 gram Ag; of this, 0.007 gram $\mathrm{Ag}$ was abstracted from solution by the quartz as shown by titration of the solution before and after contact with the quartz. Further, the quartz was then extracted with distilled water until the decantations gave no cloud with $\mathrm{KCl}$; then concentrated aqueous ammonia was poured upon the quartz, shaken up with it, and decanted. This ammoniacal extract gave a strong cloud of $\mathrm{AgCl}$ when it was acidified with $\mathrm{HNO}_{3}$ and $\mathrm{KCl}$ was added. Evidently, $\mathrm{AgNO}_{3}$ or $\mathrm{Ag}_{2} \mathrm{O}$ is held on the quartz grains. The titration with o.ooI $N \mathrm{KMnO}_{4}$ (with respect to oxygen) showed no reduction, the original silver nitrate solution and the solution removed from contact with quartz required the same quantity of permanganate to produce a coloration. The ammoniacal extract of the quartz gave no test for iron with ammonium sulphocyanate.

The area of 20 grams of this quartz being some 2000 sq. $\mathrm{cm}$, we have the value 0.0000035 gram silver-as nitrate or oxide?-per sq. cm for the absorption effect in this concentration of $\mathrm{AgNO}_{3}$.

Experiment 2.-Fine quartz flour, calculated area 740 sq. $\mathrm{cm}^{1}$ per gram, $\mathrm{HCl}$ - and water-washed, was percolated with o.oI $\mathrm{N}$ aqueous $\mathrm{AgNO}_{3}$ containing a few drops of chloroform to maintain sterile conditions. In order to avoid contamination, the percolation apparatus shown in Fig. I was used. The percolation tube $A$ expands to a wider tube at $B$ where a perforated platinum plate is sealed in the glass. The tube $A$ is inserted and the wide tube $B$ filled with coarse quartz which is allowed to settle into a filter bed $\mathrm{C}$ through distilled water or through the solution to be percolated. The tube $A$ is then placed mouth downward in the large test tube $\mathrm{D}$ which is then filled with distilled water (or with the solution to be percolated). The main filter bed of fine quartz

${ }^{1}$ Bulletin No. 59, Heat Transference in Soils, p. 35 and 50 , Bureau of Soils, U. S. Dept. of Agriculture (Igog). 
(or other absorbent powder to be studied) is now gradually poured into the large test tube and allowed to settle into the filter-bed F. Now when suction is applied at $S$ the liquid gradually passes from $E$ down through $F$, up through $C$ and over the bend in the tube, down through $\mathrm{T}$ into the receiving small test tube $\mathrm{H}$ which stands upon the bottom of the pressure flask $\mathrm{G}$.

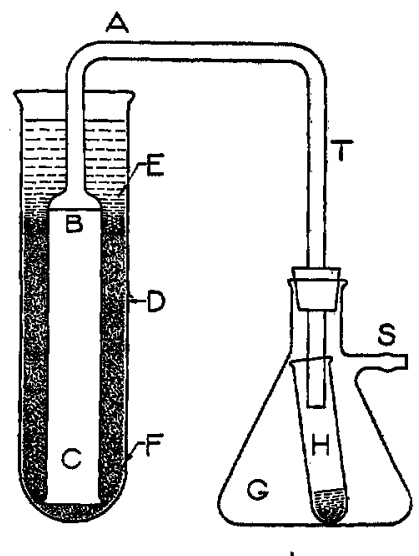

Fig. 1

$\mathrm{B}=$ perforated platinum plate.

$\mathbf{F}=$ filter bed of fine quartz.

Test-tube $\mathrm{H}$ contains water.

The percolation apparatus was cased in black paper to avoid reduction of the silver nitrate by action of light.

Blank tests were made upon the quantity of permanganate $(0.001 N)$ required to color the distilled water and the silver nitrate solution: $20 \mathrm{cc}$ distilled water required $0.4 \mathrm{cc}$ permanganate for coloration and one drop of chloroform produced no color change. Likewise $20 \mathrm{cc}$ of o.or $N$ silver nitrate solution required $0.25 \mathrm{cc}$ of $0.001 \mathrm{I}$ permanganate to give permanent color, and this was not changed by adding one drop of chloroform.

The first portion of percolate from o.or $\mathrm{N} \mathrm{AgNO}_{3}$ solution through this quartz-flour filter-bed showed an effect of reduction: $20 \mathrm{cc}$ of percolate required I.I $5 \mathrm{cc}$ of $0.00 \mathrm{I}$ per- 
manganate. It should be noted here that in this experiment the filter bed of quartz flour was formed in distilled water (sterile), consequently the percolating silver nitrate solution had to push ahead of it the distilled water contained in the filter-bed, so that this first portion does not contain all the silver nitrate which a normal percolate should. However, the reduction of nitrate to bodies oxidizable by permanganate is evident.

The second portion of percolate showed still greater reduction: Io cc of percolate required I.5 cc of o.00 I $N$ permanganate, and by titration with $0.00 \mathrm{I} N \mathrm{KCl}$ was found to contain 0.00638 gram $\mathrm{Ag}$.

The third portion of percolate gave for Io $\mathrm{cc} 0.00775$ gram $\mathrm{Ag}$, and required I.2 cc of o.OOI $N$ permanganate.

The fourth percolate for Io ec required $0.7 \mathrm{cc}$ of $0.00 \mathrm{I} N$ permanganate, and contained $0.009 \mathrm{r} 3 \mathrm{gram} \mathrm{Ag}$ per io $\mathrm{cc}$.

All of the percolates smelled strongly of chloroform. They all held extremely fine quartz particles in suspension. The effect of these suspended quartz particles upon the color produced by permanganate was found by experiment to be either negligible or not above $0.1-0.05 \mathrm{cc}$ of permanganate.

The exact total volume of each of these three percolates was not determined, the purpose here being to establish the presence or absence of surface action rather than to secure a complete quantitative percolation absorption curve.

Experiment 3.-Quartz flour washed with hydrochloric acid and with water-from the same lot used in experiment 2-was percolated with o.or $N$ silver nitrate using the apparatus shown in Fig. I, but leaving out the chloroform. The light was of course excluded during percolation. This filter-bed was formed in distilled water, so the first runnings were practically free from silver.

The first ro $\mathrm{cc}$ of percolate (total quantity percolated) required 5. I cc of $0.001 \mathrm{I}$ permanganate, whereas to cc of distilled water requires only $0.25 \mathrm{cc}$ of this permanganate solution to color it. Practically no silver was present in solution. 
The second percolate (total quantity), $8.5 \mathrm{cc}$, required I.3 cc of $0.001 N$ permanganate, and contained 0.0070 gram Ag.

The filter-bed of quartz flour contained some roo grams of quartz in experiments 2 and 3 .

Experiment 4.-Using the same form of apparatus shown in Fig. I, but with deeper filter-bed of quartz flour-200 grams quartz-distilled water containing chloroform was percolated for some time through the quartz and it was found that only $0.2 \mathrm{cc}$ of $0.001 N$ permanganate was required to color ro $\mathrm{cc}$ of this percolate. The rate of percolation under a water-head of II.5 inches was one drop in 49 seconds.

The distilled water was removed from the large test tube above the filter-bed and replaced by $0.02 N$ sodium nitrate solution containing chloroform. During 19 hours and 24 minutes $98 \mathrm{cc}$ of solution percolated-part of this being, of course, displaced distilled water-which gives a rate of 0.084 cc per minute. Ten $\mathrm{cc}$ of this percolate required only $0.2 \mathrm{cc}$ of 0.00 I permanganate for coloration, consequently no reduction of nitrate is indicated. The drops of percolate are coming one every fifty seconds under $\mathrm{II}_{1} 1 / 2$ inches water head, so it is evident that the filter-bed has not channeled. The percolate is very slightly opalescent from minute particles of quartz in suspension.

During the next 24 hours $92 \mathrm{cc}$ of solution percolated, and ro cc of this required $0.2 \mathrm{cc}$ of 0.00 I $N$ permanganate to color it.

The experiment was stopped at this point.

It appears then that under sterile conditions sodium nitrate is not reduced by contact with quartz to bodies oxidizable permanganate.

Silver nitrate solution under the same conditions shows a reduction, slight but perfectly evident. As would be expected, unsterile conditions show greater reduction of nitrate.

In Table I are given data and calculations which show roughly the magnitude of the effect produced by this surface action of quartz. Using the value $0.000,008$ gram of oxygen. 
per cc of $0.00 \mathrm{I} N \mathrm{KMnO}_{4}$, the actual weight of oxidizing oxygen supplied is calculated. If we assume that the silver nitrate is reduced to nitrite and calculate the quantity of nitrite which the oxidizing oxygen will reconvert to nitrate, a better idea of the importance of this reduction effect is obtained.

Now the quantity of silver nitrate in solution in the percolate is given (very nearly) by calculation from the silver in solution. When the ratio of (hypothetical) $\mathrm{AgNO}_{2}$ to the $\mathrm{AgNO}_{3}$ in solution is obtained, it is seen that the percent of reduction is by no means inconsiderable.

The fact that considerable permanganate is required to color the first portions of percolate, in both experiments 2 and 3 , together with the low silver content, suggests that the ratio of silver in solution is not the same in the percolate as in the original solution; the silver being low, this indicates an acid reaction in the solution. The acidity was not tested for in these experiments, as the bearing of it on this question had not been entirely appreciated then, and it was thought sufficient to titrate with permanganate to see whether reduction had taken place.

Another aspect of this reduction is, that for every 8 grams of oxygen required to oxidize the percolate 107.88 grams of silver may have been deposited from solution- 3.5 times the weight of oxygen. Consequently any experiment employing silver nitrate solution in contact with silica, or silicates or bodies capable of producing adsorption or absorption effects should be most rigidly scrutinized to insure the absence of this effect, or to determine the degree to which it enters as a disturbing factor.

Further, the fact that in experiment No. I a coarse quartz powder was found to retain silver-in some form-not washed out by water, but given up to ammonia-water, suggests that part, at least, of the reduction observed in these solutions takes the form of deposition of a compound of silver.

The negative result obtained with sodium nitrate indi- 


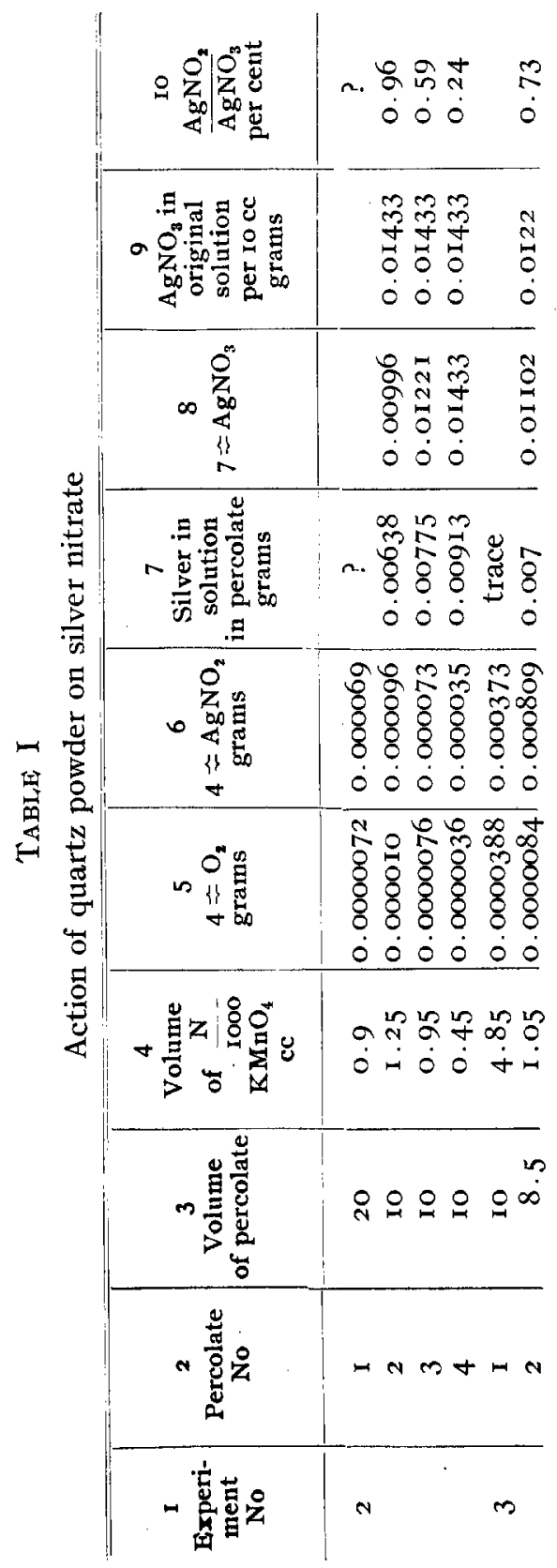


cates that the reduction of nitrate in the soil is probably due to bacterial agencies and to reduction by inorganic and organic chemical reactions rather than due to a catalytic surface effect of the soil grains. It may be that the looser combination of the heavy metal nitrates and their greater degree of hydrolysis facilitate this reduction observed for silver nitrate. The results of Graham ${ }^{1}$ with silver nitrate solution and charcoal, giving metallic silver, support this view. Likewise of Esprit, ${ }^{2}$ Moride, ${ }^{3}$ Heintz, ${ }^{4}$ Oechsner de Coninck, ${ }^{3}$ and Liebermann. ${ }^{8}$ The decrease in the quantity of oxidizable bodies in the silver nitrate solution and the increase of silver in solution as percolation proceeds (see Table I), gives further indication that the observed reduction of nitrate is due to an absorption which decreases as the absorptive capacity of the quartz surface is satisfied. Whether this absorption process is in part due to a purely chemical reaction of quartz upon silver nitrate, is an open question.

. Bureau of Soils

U.S. Department of Agriculture April I5, 1910

${ }^{1}$ Pogg. Ann., 19, 139 (1830).

${ }^{2}$ Jour. Pharm., I6, 192 (1849).

${ }^{3}$ Comptes rendus, 4I, 605 (I855).

'Liebig's Ann., I87, 227 (1877).

${ }^{5}$ Comptes rendus, 130,1627 (1900).

${ }^{B}$ Wien. Akad. Ber., 74, 33I (1877). 